\title{
Aspects of Musical Semantics from the Perspective of Structuralism, Semiotics and Narratology
}

\author{
MIHAELA-GEORGIANA BALAN \\ “George Enescu” National University of Arts Iaşi \\ ROMANIA*
}

\begin{abstract}
Music is a universal force, a widely spread mean of communication on the entire planet, because it has a strong ability to influence human emotions, even without words (when referring to instrumental or symphonic music). Thus, music is one of the most challenging arts in 'deciphering' the hidden message of its creator. The present paper is focused on three analytical techniques which imposed themselves in the musicology field of the $20^{\text {th }}$ century - structuralism, semiotics, narratology. Our purpose is to offer a general outlook on these perspectives and some specific principles of applicability when approaching a musical score, in terms of formal construction, sonorous structures, equivalence classes applied to musical elements, energetic potential of musical isotopes using modal verbs, essential aspects in determining the narrative frame (spatiality, temporality, actoriality). Structuralism, semiotics and narratology emerged as independent sciences successively, during half a century, influencing each other in a stimulating coexistence which enabled a wide scientific opening until present.
\end{abstract}

Keywords: semantics, linguistics, musical language, structural analysis.

\section{Introduction}

Music is said to be a universal language, a mean of communication between human beings, without needing words or verbal language. Since ancient times, philosophers, aestheticians, theoreticians tried to explain the inner force which lays in music, allowing people to use it in different purposes (religious, utilitarian, politic, aesthetic or for one's pleasure, either Apollonian or Dionysian). In the modern period, the great variety of sciences, research fields and theories generated a large background, which allowed the development of new directions in music analysis, with specific methods and broad artistic perspective. Music became subject for different types of approach, such as: hermeneutic description, formal analysis, psychologic ideas, Gestalt Theory, math calculus such as probability, Fibonacci sequence, Set Theory, generative grammar, etc. All these perspectives and methods create a general view on music, having a great impact on its reception and perception in listeners' conscience.

\footnotetext{
*mihaela.balan2015@gmail.com
} 


\section{General perspective on structuralism, semiotics and narratology}

Structuralism, semiotics and narratology were three directions approached in different fields of research, particularly in the history of cultures, the theory of signs and linguistic patterns used in communication, as well as in different arts. They emerged as a causal chain which had extended during a half century and enabled a wide scientific opening until present. These three directions influenced each other in a coexistential relationship which determined researchers to draw clear borders in order to separate each investigation area.

Structuralism is a plurivalent concept in the context of sciences in the $20^{\text {th }}$ century, with a wide applicability in the field of linguistics, antropology, psychoanalysis, political economy, philosophy of culture, literary and artistic critics, as well as in musical analysis. It was initially used by Ferdinand de Saussure in the field of linguistics (Cours de linguistique générale, 1914), then by Claude Lévi-Strauss as a particular method to organize concepts and information inside the anthropologic system (Anthropologie Structurale, 1958) and by Umberto Eco in his semiotic theory of sign and communication (Trattato di semiotica generale, 1975). Eventually, structuralism reached the musical field, as a technique named the paradigmatic method, used by the Belgian theoretician Nicholas Ruwet (Langage, musique, poésie, 1972) and as a concept used to identify the principle of semiological tripartition, applied in musical scores by the Canadian musicologist Jean-Jacques Nattiez (Fondements d'une sémiologie de la musique, 1975).

Semiotics developed as a particular research direction, based on the structural example offered by other disciplines and crossed a long journey until its present status as an independent science of meaning, interfering with the theories of communication and the philosophy of language. Initially, semiotics was mentioned in the General Linguistics Course written by Ferdinand de Saussure (first edition, in French - 1914; Romanian edition - 1998), who used a different term - semiology - and explained it as dyadic pattern of classifying the components of the sign - the signifier and the signified. In America, another researcher, Charles Sanders Peirce, set the basis of semiotics, in which he theorized the sign and its parts from a different perspective, considering the structure of sign as a triadic pattern, represented by representamen, object and interpretant. Modern semiotics was approached by Umberto Eco (first edition, in Italian - 1975; Romanian edition - 1982), who formulated the definitions of sign, referent, iconicity from a new perspective, including communication codes, interpretation and information theories. The semiotic field is organized in three directions of research, corresponding to the triple function of signs: syntactic-semantic-pragmatic. Therefore, syntax concerns the network of relations between signs, focusing on the formal aspect of the discourse, semantics refers to the relations between signs and objects/concepts, while pragmatics has as research aim the entire ensemble of connections between 
signs and speakers, the psychological and sociological relations between users of signs and expressions. As concerns the position of semiotics among other sciences, one must consider the multidisciplinary basis of this field and the permanent process of interfering with aesthetics, philosophy, psychoanalysis, hermeneutics, mathematics, logic, etc. But one can't agree with the idea of semiotics as a hybrid field, a simple result of other former disciplines research, because it had gained an autonomous status as a modern field, based on ancient premises of almost 2000 years. Moreover, general semiotics has its particular methods of research and analysis, which can be applied on different objects concerned during the scientific investigation.

Narratology detached from the multiple directions of literary research and semantic interpretation which had been approached by semioticians. It refers to a general wide-spread tradition in all cultures and fields, concerning the principles of narration, organised as genuine "laws" of presenting a succession of events, in a certain temporal order chosen by the narrator. It refers to passing from a previous state of things to a certain subsequent order, generated by the earlier situation or event. In literature, narratology was introduced in order to analyse the process of telling a story, which became, in a general perspective, a science of narration, a particular method to analyse a discourse. Among the first researchers who created the scientific frames of the new branch of study were Roland Barthes, author of a genuine narratological manifesto - Introduction to the Structural Analysis of Narratives (1966) -, Tzvetan Todorov, who imposed the term of "narratology" to name the science focused on the art of telling stories (Todorov, 1969). Other founders of this discipline were Gérard Genette, who was one of the most influential narratologists of the $20^{\text {th }}$ century, Algirdas Julius Greimas, as a representative figure of the French semiotic school, Claude Bremont, who was concerned with the logic of narrating.

\section{Music between artistic and linguistic approach}

In the musical field, structuralism, semiotics and narratology were approached by borrowing specific terms used in other fields, generating a complex research system with interdisciplinary connections. Over time, musical analysis has constantly diversified its techniques, changing its approach and objectives depending on the followed issues. Structuralism, as a largely applicable concept, can be also used in the musical field, where structure became an essential concept for the $20^{\text {th }}$ century musicology. It is mainly used in the analysis of musical forms (at both micro- and macrostructural level), but also for the harmonic analysis, the writing manner of composition and the other musical language parameters. Structure can be defined as "an emerging totality of sonorous objects which tends to be conserved" (Şurianu, 2008, p. 526) and refers to a particular inner order, governed by specific laws of the sonorous unfolding, which are necessary to accomplish a genuine musical grammar. 
The relations between the whole and its components, between structure and content, diversity and unity represented a highly interesting point for musicians from the Romanticism period, when musical writings about meaning had reached a similar aspect to the literary field. This is why many articles and texts about music in the $19^{\text {th }}$ century were written in a different manner, with metaphoric language and belletristic manner of expressing ideas. (Bent, 1994) This stage can be considered a process of associating musical meanings with concrete aspects of life and different human feelings. The connection between the structural components of a musical work became a much more concerning object of interest for musicologists, who began to develop a stronger tendency towards emphasizing the musical meaning based on the analysed elements of the sonorous structure. Therefore, the semantic level of a musical work would be approached from many points of view, starting with the general structure and the organizing principles.

In the $20^{\text {th }}$ century, the musical thinking became more and more focused towards the idea of construction, due to the "emergence of structuralism" and the "semiotic-linguistic conjunction" . "Being applied to the structure, musical analysis found itself in a paradoxical situation of being designated as structuralist, because the redefinition of conception and its instruments happened as a result of some transfers (with the necessary adjustments) from the structural linguistics and semiotics. Considering the structural reality of a musical work in a theoretical references system, in categories and laws of organization and also in an ensemble of essentially different conventions than classical principles, the initiative of structural analysis is - in both historical and epistemological perspectives - a 'head-series' of the deep transformations which musical analysis has crossed in the last decades of the $20^{\text {th }}$ century" (Firca, C. L., 2008, p. 35). In other words, a musical work represents an independent, functional system, built on a structural basis that is balanced by the equilibrium between whole and parts, similarly to the linguistic field where any system of communication is based on a hierarchically stratified organization.

The purpose of structuralism in the musical analysis is, therefore, the intention to focus on the sonorous substance itself, because any artistic creation is considered a finite product, a concrete result of the composition activity perceived as an autonomous act. The need for scientific rigour in any analytical process leads to the use of methods with linguistic origin and the organization of the musical discourse on many levels, layers, parameters, categories, similarly to the principles that were borrowed from other fields. A relevant

\footnotetext{
${ }^{1}$ Both syntagmas belong to Jean-Jacques Nattiez, apud Firca, C. L. (2008), “Analysis”, in Dictionary of Musical Terms, p. 35.
} 
example is given by the terms morphology and syntax which are used as main categories of structural components of the musical forms.

In order to understand at a higher level the relation between linguistics and music by using structural methods, we will present the perspective of the famous conductor, composer and pianist Leonard Bernstein, who has approached this complex issue through some edifying examples, demonstrating the validity of the techniques applied in both fields. He was invited to become a professor at the Harvard University at the Charles Elliot Norton Department of Poetry, where he had to teach for one year, counsel students and prepare six public lectures. L. Bernstein focused his lectures on the musical meaning related to linguistic systems, poetic concepts and aesthetic criteria of artistic value:

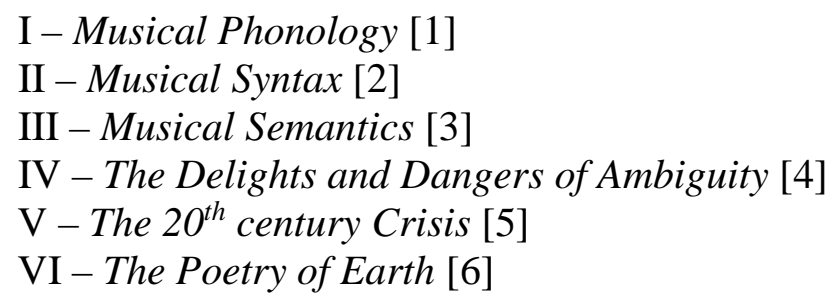

Starting from the concept of "monogenesis", L. Bernstein set the premises for establishing a common basis for music and language in all cultures of the worlds, where semantics (referring to meaning, signification) is a result of two other linguistic branches, phonology (the study of sound, based on the natural resonance) and syntax (the analysis of structure, aiming towards the connection between sounds themselves and musical parameters: melody, harmony, rhythm, timbre):

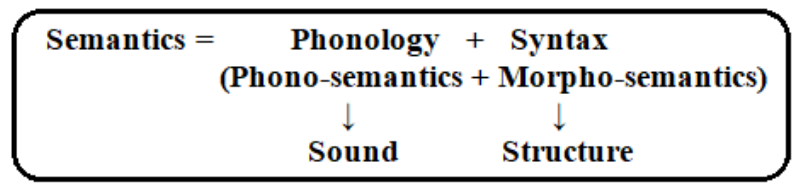

Fig. 1 Semantic perspective on music, related to verbal language

Moreover, there can be established certain equivalences between the musical and the verbal language, from the smallest structural elements to the complexity of an entire work or coherent text [Bernstein, 1973, 2nd lecture].

\begin{tabular}{|c|}
\hline note $=$ phoneme (a sound, such as $\mathrm{m}, \mathrm{n}, \mathrm{a}, \mathrm{e}$ ) \\
\hline motive $=$ morpheme (a syllable, such as ma) \\
\hline musical phrase $=$ word \\
\hline section $=$ clause \\
\hline movement (from a work) $=$ phrase \\
\hline musical work $=$ text \\
\hline
\end{tabular}

Table 1 Equivalences between the musical and the verbal language 
The fifth equivalence (in which a movement from a work corresponds to a verbal phrase) might generate confusion, because in German, satz means both movement and proposition. Bernstein indicates that not all perfect cadenzas are marks of "musical phrases", as it happens in verbal language, where a period means the end of an idea. Therefore, in music, we have the impression of hearing many musical ideas in a single work or in a movement of symphony, concert, quartet, et cetera, where connections between musical propositions are created by using specific "conjunctions", "relative pronouns or adverbs" (which can be suggested by certain motives or accompaniment formulas, certain harmonic relations which might generate the impression of continuation, pause or stop).

Moreover, Bernstein created analogies between morphological elements of grammar and musical language components. For example, a certain motive or leitmotive might be seen as a noun (on the horizontal level), whereas the harmonic structure of the chord gains the value of adjective (on the vertical level), generating specific features for the idea suggested by the previous "noun". There is also the idea of action, corresponding to verbs, created by certain types of rhythms which suggest the power of the previous leitmotive to influence the evolution of the musical discourse.

A very interesting aspect of musical language is the process of transforming propositions by using different techniques:

a. deletion (of some words in order to avoid unnecessary and disturbing repetition);

b. embedding (of many clauses in a single phrase);

c. permutation (of certain elements which must change their location after applying the previous transformations);

d. pronominal substitution ("pronominalization", which leads, in music, to different modified versions of the initial leitmotive).

e. conjunction, which in spoken language results from joining many clauses in the same phrase, in order to accomplish an extended meaning, while in music, conjunction appears when the end of a musical motive, phrase or idea is the beginning of the next sequence at the same time.

In the following table [Bernstein, 1973, 2nd lecture], Bernstein organized the levels of meaning in music and poetry, in order to highlight the existence of a deep structure which generates the superior strata towards the visible artistic surface. The most important idea emphasized by Leonard Bernstein is the existence of a higher level inside the linguistic structure, which can't be considered art, because it has a specific function - to communicate ordinary facts. From this reason, music appears at the surface structure as a perfectly coherent artistic language (level $\mathrm{D}$, because it has a single aesthestic function), while verbal language is considered to be simply a prose structure and is located at an inferior level (C). To reach the artistic function of expressing higher 
meanings, verbal language has to go further in its transformational process, becoming poetry. This is the level of equivalence between music and poetry, where both arts fulfil the necessary aesthetic conditions.

\begin{tabular}{|l|l|}
\hline \multicolumn{1}{|c|}{ Verbal language levels } & \multicolumn{1}{c|}{ Musical language levels } \\
\hline D: Poetry (Super-Surface Structure) & D: Music (Surface Structure) \\
\hline$\uparrow$ & \multicolumn{1}{c|}{$\uparrow$} \\
\hline C: Prose (Surface Structure) & C: “Prose” (Deep Structure) \\
\hline$\uparrow$ & \multicolumn{1}{c|}{$\uparrow$} \\
\hline B: Underlying strings (Deep Structure) & $\begin{array}{l}\text { B: Underlying strings (melodic, } \\
\text { harmonic, rhythmic) }\end{array}$ \\
\hline$\uparrow$ & $\uparrow$ \\
\hline $\begin{array}{l}\text { A: chosen elements (morphemes, words, } \\
\text { etc.) }\end{array}$ & $\begin{array}{l}\text { A: chosen elements (key, time } \\
\text { signature, etc.) }\end{array}$ \\
\hline
\end{tabular}

Table 2 Structure of poetic and musical language - comparative table

In his third lecture, Leonard Bernstein approaches the subject of ambiguity, which is a common feature to both poetic and musical language. The semantic perspective in music is focused on different elements than poetry, but the process of transforming feelings and ideas into artistic language is based on common stages and techniques. As an example, he mentions the term zeugma which leads to confusion in verbal language by extending the meaning of some words and associating unexpected terms. In literature and poetry, it is used as a deliberate artistic technique. One of the most relevant literary means of expression concerning ambiguity is the metaphor, which replaces an element with another one, as a result of certain implied comparison between them, based on common features.

$$
A \leftrightarrow B \text { (based on a common element, } x \text { ) }
$$

Of course, the background process of connecting A and B by discovering the intermediary element (or elements) must be remade by the receiver (reader, listener), gaining often new meanings in his personal perspective. During the interpretation of these artistic methods, Bernstein draws attention on the difference between meaning and expression: the former refers to the objective, intrinsic meaning of music and the latter corresponds to the subjective aspect, related to the listener.

The Belgian musicologist, linguist and literary critic Nicholas Ruwet wrote about a key factor, the repetition principle, which may be found in all levels of existence and culture. Speaking about this aspect, Bernstein quotes the famous linguist and theoretician Roman Jakobson (Bernstein, 1973, 3rd lecture): "It is only by the regular reiteration of equivalent units that poetry 
provides an experience of time comparable to that of musical time.” In music, repetition involves not only the identical segments which can appear again in a given fragment, but also those elements which were transformed by different musical techniques (inversion on melodic direction, change of intervals between sounds, augmentation or diminution of rhythm, transposition of a musical unit on other notes or in different keys, etc.) These are important aspects in the process of elaborating a "musical discourse", in order to avoid monotony and to make it comprehensible, coherent, interesting to follow; in other words, we say it has to be meaningful.

The example of modern poetry is full of artistic means used by poets of the $20^{\text {th }}$ century in order to increase ambiguity, creating great masterpieces in which every word is a particular entity of the spiritual universe of the poetry. Bernstein explains the intersection of poetic and musical languages by offering a very simple image on artistic concepts and aesthetic meanings in both arts.

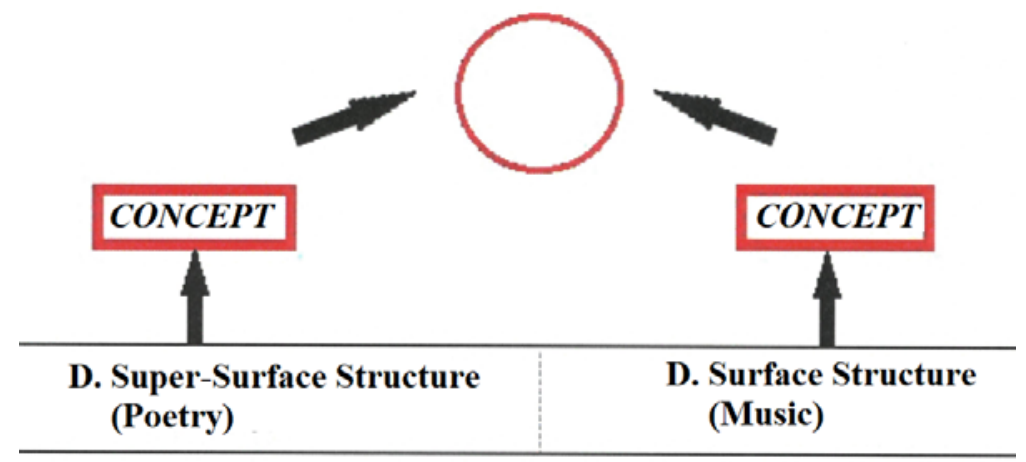

Fig. 2 Final sketch of reaching semantic meaning and intersecting artistic languages

The final unification of the two concepts is given by certain compatible elements which result from the previous semantic process, leading to a common level of meaning. It can be imagined as a new artistic entity, as a pure act of creation, with its own inner meaning and power of suggestion.

In his highly valuable academic lectures, L. Bernstein has approached many issues of the musical structures and its semantic dimension, elaborating a parallel perspective between between the linguistic and musical fields, by associating the hierarchical categories of their specific organisation. Bernstein's viewpoint is an ambitious statement of musical analysis principles, offering an inspiring source in understanding a musical score. His perspective is elitist, clear, sensitively argued and based on a rigorous research. 


\section{Methodological aspects concerning the application of structuralist, semiotic and narratological principles in the musical analysis}

Musical analysis focusing on structural, semiotic, narratological elements must start from the premise that these methods imply certain risks. When it comes to combine musicological techniques with other perspectives, one must be aware of two aspects: on the one hand, the constant interpenetration, the intertwining process between these fields and their principles (also interfering with psychological, hermeneutical, aesthetic, stylistic and other directions); on the other hand, there is a problem of incompatibility between certain methods and some musical works, due to their stylistic features, genre, historical period and other strict musical elements. From these reasons, these types of analysis can't be pure (which refers to strict application of some methodical principles), because it is necessary to combine different procedures so as to emphasize the compositional technique, the structure of musical discourse and semantic substrate. However, any musical analysis must begin with a general and detailed perspective on the musical form and structural elements, which is the basis of any investigation, no matter its purpose.

One of the major problems of any structural analysis of a musical work is the adjustment of linguistic principles and terminology, leading to a complex process of transposing the methods of interpretation signs and meanings. The notion of musical discourse, which is frequently used in the contemporary musicology, is originated in the field of linguistics and the sciences of communication, having tangent connections with the general principles of the rethoric field. In music, creating a discourse should consider all its levels of existence: the score (which is an immanent form of existence, related to the historic factors, the context when a work was composed), the act of performance (the existence in fact of music, given by the temporal coordinate of playing or singing in a moment of time which could be associated with present continuous) and the memory of the audience (the level that can't be considered a proper discourse, because after the end of performing and listening a work, the process of decoding the message reaches another phase of existence, from active to passive, from ephemeral to eternal). At this level, the echo of the audition remains as psychological sign, marked by the listeners' infinite subjectivity and ability of understanding.

During the last decades, musicologists have tried to create a clear, coherent system, as close as it can be to the musical structure reality, by using linguistic notions and ideas in order to improve the process of understanding artistic creations. The Romanian musicologist Gheorghe Firca mentioned a few terms used in the field of musical analysis and which had been borrowed from other scientific languages: "the non-semantic character of music, the nonidentity between the artistic language and the current, notional language, the existence of a musical content itself or, in extremis, the absence of this content.” (Firca, G., 1974, p. 56). These terms indicate the approximate aspect 
of the musical signified, the impossibility to imagine it in tangible state or, at least, as a concrete representation. In music, there is a high risk to fall into approximations and metaphors, which made Nicolas Ruwet express his opinion that "it is necessary to establish many abstracts levels of representation, each of them being characterized by a system of units and particular laws", in order to create a strong connection between the by using "strict rules of representation". (Ruwet, 1972, p. 11) Starting with these considerations, he gave up the general terminology used when analysing musical forms (motive, phrase, period, theme) and introduced a new method of approach based on the recognition of musical elements that impose themselves through reiteration. He intended to use a semiotic system of analysis in order to emphasize the connection between words and music by arranging all the musical units in synthetic tables in which the vertical columns are based on common semantic features. The process of transformation of the initial musical material enables the unity of the sonorous discourse and has the function to organize its evolution according to intrinsic criteria, which are discovered during the unfolding of the musical work. The paradigmatic principle used by Ruwet generates equivalences between morphological units of the musical discourse, offering a synthetic perspective on music in general, inspired by the mythological analysis used by Claude Lévi-Strauss. He compared the reading of a myth with the performance of an orchestral score, which enables the discovery of the most intimate connections among its smallest components.

The generative grammar, which inspired many musicologists in their analytical works, "is focused on the enumeration of different types of wellconstructed phrases and discourses (by assigning a certain structural description), which are possible in given language" (Ruwet, 1972, p. 15). As in general linguistics, the idea of possible human language refers to specific restrictions imposed by its grammar laws, similarly, a poetical or musical grammar should aim at following an ensemble of artistic works which are possible in the case of a certain author (poet, writer, composer), in a certain culture or style, by using a particular system of rules. The example offered by Noam Chomsky in the linguistic field generated a new way to analyse a musical score by considering its components as units organized according to specific grammar rules, in order to create a syntagmatic tree. The unfolding of the sonorous discourse can be followed in hierarchical settlement, structured in three levels: inferior level (III) which is subordinated to the medium one (II), whose components are dominated by another superior level (I). The main criterion imposed by Ruwet in this system is the length of units. Therefore, musical segments with the same structure are integrated in the same level, without relating to the formal terminology used in musical analysis (motives, phrases, periods). The length that Ruwet mentions is quite imprecise, because musical units have many levels of differences, related to the density of notes, 
rhythm, tempo. This aspect leads to the segmentation of the sonorous discourse by following the continuity of its unfolding, by keeping the order of events which form, together, a complex structure with semantic meaning.

A very important element used in linguistics and applied in music is the sensitiveness to context, which generates the classes of equivalence. "When two distinct musical elements have a common context or an ensemble of possible contexts in a work or a given repertory, they can be described as functional equivalent elements; the totality of features which have identical contexts create a class of equivalences.” (Bent \& Drabkin, 1998, p. 170) This point of view leads to a new form of organization, according to the preponderance of their return (by reiteration or variation) and their features which generate the similarities between segments, leading to a paradigmatic structure. In Ruwet's opinion, the value of this method is given by "the application of simple principle of analysis, proposed by structuralist thinking and the exigency of formal perspectives", which "allowed the introduction of incontestable strictness in the field of musical analysis" (Ruwet, 1972, p. 17). Of course, any type of art (literary, visual, kinetic, musical) possess a particular code which allows the access to unique message. Analytical methods, no matter how complex they are, can't guarantee the exhaustive understanding of encoded meanings by using other types of language; and generative grammar presents the same risk.

When a musical work has a clear structure, it enables a detailed form analysis, with all component units which can be organized in hierarchical levels, generating a general sketch of the macrostructure. This method can be considered a taxonomic technique that can be applied to a musical work, leading to a tree-like image of its internal organization. The microstructural elements (motives, cells, figures) can be analysed by using a particular method, approached in music by musicologist Jean-Jacques Nattiez in his volume - Fondements d'une sémiologie de la musique (Nattiez, 1975). It refers to a detailed classification of all microstructural units into classes of equivalence, based on their common features and their transformation during the musical discourse. This classification is realised by organizing all microstructural units in a paradigmatic table, which also contains symbolic indicators, marked by capital letters which refer to specific melodic or rhythmic features (explained separately). The final table is relevant for the logic of the score, the fluency of the discourse, the variational potential of musical motives, leading to a very consistent perspective on the structural and stylistic coherence of the analysed work.

Therefore, the structuralist approach leads to the discovery of the particular meanings which lie at the bottom of the semantic substrate of the music. The purpose of semiotics is to emphasize the multiple connections established between all components of the discourse, by accomplishing a systematic analysis, organized in many sections, according to the musical 
parameters and grammar layers, in order to reach a functional hierarchy of all sonorous units and to individualize each segment in the context of the entire semantic ensemble. As the Romanian musicologist Antigona Rădulescu observes, the function of the semiotic approach in a musical analysis can be identified in two main directions: "On the one hand, it refines the process of observing the grammatical dimension, considering both components of the musical language - syntax and vocabulary; on the other hand, it requires the necessity to form and reinforce the semantic demarches (in direct connection with grammar) that are usually ignored by traditional analysis." (Rădulescu, 2013, p. 65)

Narratology can be used in music as an alternative interpretation of a particular work, which is neither lyric theatre (opera, operetta, musical comedy, ballet), nor program music (involving an extra-musical narrative). The concept of narrativity (different than narration, which refers to the act of telling a story) can be applied to music as a supra-structure idea, as a system endowed with the ability to shape and influence the sonorous discourse according to specific laws. In a general perspective, one could speak about a narrative dimension in a musical score which has an evolution by variation, elaboration, development of certain musical material, leading to a genuine musical dramaturgy.

Narrativity could be identified on two levels: on the one hand, in the musical work itself, which refers to the logic of score, the construction of the sonorous discourse. This aspect reminds the well-known opposition between pure, absolute music and descriptive, programmatic music. On the other hand, the musical performance can also have narrative features, because the player (or the singer) has the ability to give particular meanings to the music he performs (meanings which can be close to the historical and stylistic context when the work had been composed or with different intentions, more personal and intimate).

The Finnish musicologist and semiotician Eero Tarasti comes with two specific terms which define these aspects of musical narrativity: statement - the music itself, written in the score - and enunciation - the performance (In the French version, the terms are énoncé and énonciation - Tarasti, 1996, p. 42). These elements prove a type of narrativity which appears only as a result of a temporal unfolding of musical discourse and can't be analysed without considering the interaction between subject and object during the "musical communication". This idea is based on certain tensions generated as internal movements, which give an energetic charge in the evolution of the musical work.

The following figure represents a global image of the elements that compose the narrative frame where a musical discourse unfolds. 


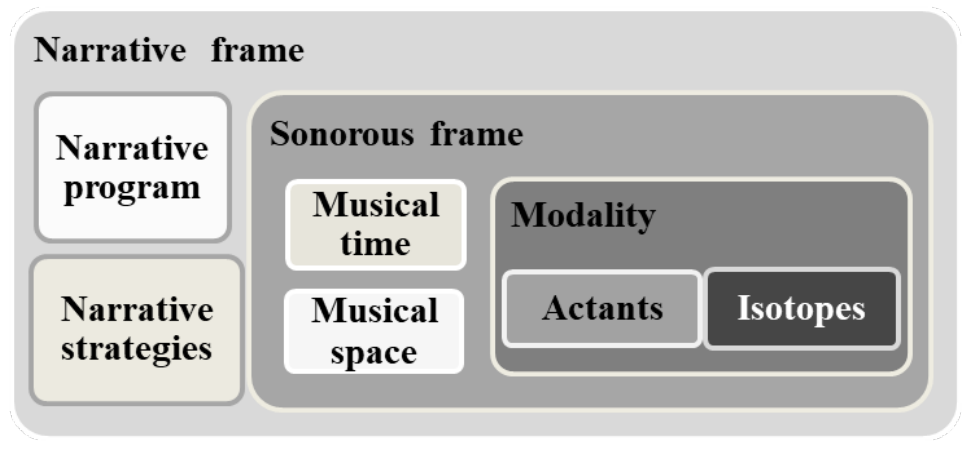

Fig. 3 General image of a musical narrative construction

It is interesting to discover new meanings in works which have a strong plasticity of melodic lines, harmonic chains, rhythmic pulsation, particular timbres, sonorous textures, suggesting different images, ideas, feelings. Musical discourse is similar to a narrative thread, like a storyline, due to the diversity of sonorous material and the striking character suggested by musical themes. The narratological analysis involves specific elements, such as isotopes and their semantic functions; essential aspects in determining the narrative frame - spatiality, temporality, performership -; narrative units or programs that form together a musical discourse; modalities (to do, to be, can, must, to want, to know) and potential of actants in each program; narrative strategies used to establish isotopes and coherence in the discourse.

Isotopes are the first criteria used for the analysis of musical discourse. The definitions offered by Tarasti for this term (with origin in the field of physics) are related to both aspects of formal segmentation and semantic signification: the first idea is that isotopes are "levels of meaning in a certain text, serving as main factor for the segmentation of the analysed work" (Tarasti, 1996, p. 79); another reference about isotopes is about "semantic fields located at the deepest level of meaning, where signification becomes recognizable.” (Tarasti, 2006, p. 24). The general idea of the analytical system conceived by Tarasti is that signification appears as an abstract idea, coming from deep resources of the discourse where lays its essence and ensures its coherence. Isotopes are levels of meaning perceived as dynamic (not static) entities, because they progress, transform, develop or diminish their force of affirmation, creating a "living discourse".

Spatiality, temporality and performership are categories which generate articulations of the musical flowing, time organization, involving thematic elements as well.

Musical space represents the place where isotopes manifest themselves, referring to two aspects: external space (totality of registers where music unfolds, which leads to the ambitus - sonorous extent - of an instrument or placement of instruments in the case of chamber or orchestral music) and 
internal space (defined by an organic movement of harmony, rhythm, less visible aspects of music).

Musical time is a complex concept, which has been defined, classified theorized by numerous musicians, philosophers, physicists, generating polemical discussions with valid arguments and stimulating opinions on every side involved. Tarasti tried to narrow the entire problem for the semiotic field by indicating two paradigms: memory (which refers to the succession of musical events in the mind of the listener) and expectancy - term originating in the field of psychology (which is generated during the unfolding of musical performance, when sonorous events accumulate and agglomerate, gaining a specific course, a certain direction in the mind of the listener, sometimes predictable, other times with unexpected deviations). Tarasti emphasized that this level "reaches the highest point at the beginning of a work, when the audience doesn't know anything about what will happen, having an empty space at the horizon of his musical expectation.” (Tarasti, 1996, p. 39) Concerning memory and expectancy, there are intersections between musical semiotics and the theory of information, because the terms of entropy and redundancy are introduced in order to describe the quantity of musical information stored in the mind of the listener.

In this artistic frame, defined by two dimensions - space and time - one discovers another element of the musical evolution: the existence of certain "heroes", defined by an individual profile and a dominant feature. Performership is a foreign term for music, borrowed from the dramatic art of theatre, suitable for classifying these levels of sonorous signification. The theatrical level is composed of many musical ideas, characterized by a certain specificity of the characters. In Tarasti's opinion, performership "is attached to the anthropomorphic side of music" (Tarasti, 1996, p. 40), referring to connections between themes and different other ideas transposed in music (abstracts ideas, in the case of pure music, or concrete features, in the case of descriptive music, suggesting a human character typology, a symbolic element, a certain situation).

Besides these categories of structural units and unfolding levels, Tarasti introduced in his analysis certain terms related to harmonic, rhythmic or dynamic movement, which aim, in fact, towards moments of progressive tension, climax and energetic relief of the discourse. Pairs of terms such as embrayage - débrayage (French terms), internal - external, nucleus (core) periphery, centripetal - centrifugal, designate intrinsic forces which operate at the level of musical meaning, listeners' feelings, mobilizing or releasing the concentration on the sonorous events.

Modalities result from spatial, temporal and theatrical aspects which define the state of a certain isotope. Although they seem to be subjective or arbitrary interpretations inserted in the discourse, modalities have an essential 
function in determining the potential of motives, their mobility to evolve, transform, unfold into larger musical ideas, generating that bow shape (constructed from the beginning by exposing, tensioning, culminating towards the ending). The most important verbs used to express modality are to be (referring to the initial state of the sound, the absence of tension, neutrality, stability, consonance) and to do (indicating action, event, dynamism, dissonance). The alternation between tension (to do) and relaxation (to be) is considered to be the simplest form of narrativity. Other modalities are expressed by the following verbs:

- to want (associated with kinetic energy, the tendency to advance towards something, with a certain purpose);

- to know (indicating the information provided by music, its cognitive potential);

- can (referring to the strength of music, the efficiency of its message, of its technical resources; this quality is obvious in writing manner of the composer and also in the musical talent and virtuosity of the performer);

- must (related to order imposed by elements such as genre, form, relation between a musical work and the aesthetic, stylistic, technic features of a certain historical period);

- to believe (indicating the truth value of music, its ability of persuasion during the performance/ listening process, generating associations with aspects such as verisimilar - non-verisimilar, appearance - essence, etc.)

Modalities can't be assigned to arbitrary structural units in a work, because they can be discovered in the structure of the musical discourse as immanent elements of meaning, located in the background level. Modality provides a signification which represents "a semantic dimension without specific semantic content.” (Tarasti, 1996, p. 225) Therefore, it indicates the existence of a structural logic inside the message. Likewise, another observation made by Tarasti is about establishing the right modalities in musical discourse, by considering the style of the epoch, the vision of the composer, the cultural, historical ad geographic context where belongs a certain musical work.

Music is not just a sign among many others, which would lead to a necessary decoding process and interpretation of its message, but rather a logic consequence of signs, a mean of communication which develops and gains its own value by having a particular form of narrativity.

\section{Conclusions}

In a musicological research, structural analysis - based on taxonomic principles and paradigmatic methods - and semiotic analysis - aiming towards the association of the units and the artistic meaning generated by music require a very detailed and technical work, by setting the musical material beneath the objective lentil of segmentation, organisation, classification, 
establishing connections between all levels of structural units and observing the principles applied by the composer himself/herself. The narratological approach is a different perspective on a musical discourse, offering a much wider analytical framework, due to the high degree of freedom inside semantic interpretation. All these methods have in common their deep and distant origins in the linguistic field, bringing new directions of investigation in the musicology of the $20^{\text {th }}$ century.

\section{References}

Bent, J. D. (1994). Musical Analysis in the Nineteenth Century, vol. II - Hermeneutic Approaches. Cambridge: Cambridge University Press.

Bent, I.; Drabkin, W. (1998). L'analyse musicale - Histoire et methods. Paris: Editions Main d'Oeuvre.

Eco, U. (1982). Tratat de semiotică generală (after the original edition Trattato di semiotica generale from 1975). Bucureşti: Editura Ştiinţifică şi Enciclopedică.

Firca, C. L. (2008). Analiză [Analysis]. In Firca, G. (Ed.), Dicţionar de termeni muzicali [Dictionary of Musical Terms] (34-37). Bucureşti: Editura Univers Enciclopedic.

Firca, G. (1974). Logos musical et structure. Revue roumaine d'histoire de l'art, série Théâtre, Musique, Cinéma, XI, 55-65. Bucarest: Académie des Sciences sociales et politiques de la République Socialiste de Roumanie.

Lévi-Strauss, C. (1978). Antropologia structurală [Structural Anthropology]. Bucureşti: Editura Politică.

Nattiez, J. J. (1975). Fondements d'une sémiologie de la musique. Paris: Union Générale d'Editions.

Rădulescu, A. (2013). Introducere în semiotica muzicală [Introduction in Musical Semiotics]. Bucureşti: Editura Muzicală.

Ruwet, N. (1972). Langage, musique, poésie. Paris: Editions du Seuils.

Saussure, F. de (1998). Curs de lingvistică generală [Course of General Linguistics]. Bucureşti: Polirom.

Şurianu, H. (2008). Structură [Structure]. Firca, Gh. (Ed.), Dicţionar de termeni muzicali [Dictionary of Musical Terms] (526-527). Bucureşti: Editura Univers Enciclopedic.

Tarasti, E. (2006). La musique et les signes - Précis de sémiotique musicale. Paris: Editions de l'Harmattan.

Tarasti, E. (1996). Sémiotique musicale. Collection Nouveaux Actes Sémiotiques. Paris: Pulim. 
Todorov, T. \& Weinstein A. (1969). Structural Analysis of Narrative. NOVEL: A Forum on Fiction, 3 (1), 70-76. Durham: Duke University Press.

\section{Websites}

Bernstein, L. (1973). Norton Lectures. Retrieved April 1-30, 2016, from www.youtube.com:

[1]<https://www.youtube.com/watch?v=8fHi36dvTdE\&list=PLKiz0UZowP2V0mwt Nv1lc1_zUSB2O65d7> (1st lecture)

[2]<https://www.youtube.com/watch?v=r_fxB6yrDVo\&list=PLKiz0UZowP2V0mwt Nv1lc1_zUSB2O65d7\&index $=2>$ (2nd lecture)

[3]<https://www.youtube.com/watch?v=8IxJbc_aMTg\&index=3\&list=PLKiz0UZowP 2V0mwtNv1lc1_zUSB2O65d7> (3rd lecture)

[4]<https://www.youtube.com/watch?v=hwXO3I8ASSg\&list=PLKiz0UZowP2V0mw tNv1lc1_zUSB2O65d7\&index $=4>$ (4th lecture)

[5]<https://www.youtube.com/watch?v=kPGstQUbpHQ\&index=5\&list=PLKiz0UZo wP2V0mwtNv1lc1_zUSB2O65d7> (5th lecture)

[6]<https://www.youtube.com/watch?v=OWeQXTnv_xU\&list=PLKiz0UZowP2V0m wtNv1lc1_zUSB2O65d7\&index=6> (6th lecture) 